\title{
UNIVERSITYOF BIRMINGHAM

\section{Concentrations of Polybrominated Diphenyl Ethers, Hexabromocyclododecanes and Tetrabromobisphenol-A in Breast Milk from United Kingdom Women Do Not Decrease over Twelve Months of Lactation}

\author{
Harrad, Stuart; Abdallah, Mohamed Abou-Elwafa
}

DOI:

10.1021/acs.est.5b00539

License:

Creative Commons: Attribution-NonCommercial (CC BY-NC)

Citation for published version (Harvard):

Harrad, S \& Abdallah, MA-E 2015, 'Concentrations of Polybrominated Diphenyl Ethers,

Hexabromocyclododecanes and Tetrabromobisphenol-A in Breast Milk from United Kingdom Women Do Not Decrease over Twelve Months of Lactation', Environmental Science \& Technology.

https://doi.org/10.1021/acs.est.5b00539

Link to publication on Research at Birmingham portal

\footnotetext{
General rights

Unless a licence is specified above, all rights (including copyright and moral rights) in this document are retained by the authors and/or the copyright holders. The express permission of the copyright holder must be obtained for any use of this material other than for purposes permitted by law.

- Users may freely distribute the URL that is used to identify this publication.

- Users may download and/or print one copy of the publication from the University of Birmingham research portal for the purpose of private study or non-commercial research.

-User may use extracts from the document in line with the concept of 'fair dealing' under the Copyright, Designs and Patents Act 1988 (?) - Users may not further distribute the material nor use it for the purposes of commercial gain.

Where a licence is displayed above, please note the terms and conditions of the licence govern your use of this document.

When citing, please reference the published version.
}

Take down policy

While the University of Birmingham exercises care and attention in making items available there are rare occasions when an item has been uploaded in error or has been deemed to be commercially or otherwise sensitive.

If you believe that this is the case for this document, please contact UBIRA@lists.bham.ac.uk providing details and we will remove access to the work immediately and investigate. 
This document is confidential and is proprietary to the American Chemical Society and its authors. Do not copy or disclose without written permission. If you have received this item in error, notify the sender and delete all copies.

\section{CONCENTRATIONS OF POLYBROMINATED DIPHENYL ETHERS, HEXABROMOCYCLODODECANES AND TETRABROMOBISPHENOL-A IN BREAST MILK FROM UNITED KINGDOM WOMEN DO NOT DECREASE OVER TWELVE MONTHS OF LACTATION}

\begin{tabular}{|r|l|}
\hline Journal: & Environmental Science \& Technology \\
\hline Manuscript ID: & es-2015-005396.R1 \\
\hline Manuscript Type: & Article \\
\hline Date Submitted by the Author: & $\mathrm{n} / \mathrm{a}$ \\
\hline Complete List of Authors: & $\begin{array}{l}\text { Harrad, Stuart; University of Birmingham, Division of Environmental Health } \\
\text { \& Risk Management } \\
\text { Abdallah, Mohamed; University of Birmingham, Division of Environmental } \\
\text { Health \& Risk Management }\end{array}$ \\
\hline
\end{tabular}


*Author for correspondence

email: $\underline{\text { S.J.Harrad@bham.ac.uk }}$

Tel: +44 1214147298

${ }^{1}$ School of Geography, Earth and Environmental Sciences, University of Birmingham,

Birmingham, B15 2TT 


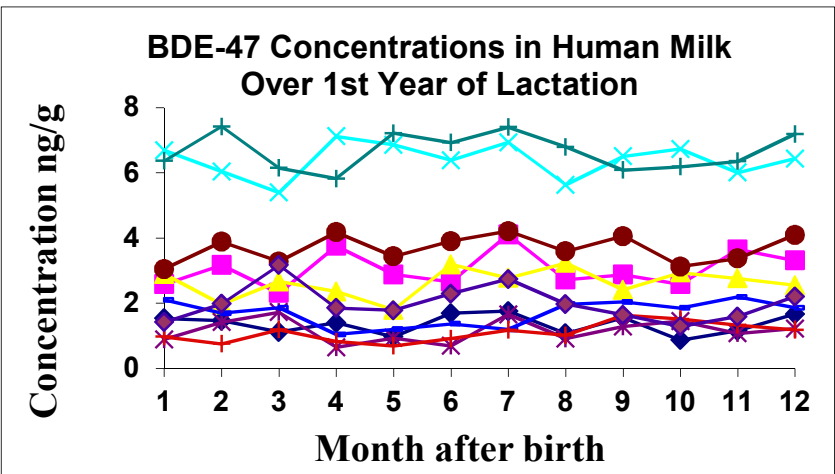

24 


\section{Abstract}

26 Conflicting evidence exists about whether concentrations of persistent organic chemicals in

27 human milk decrease over the course of lactation. This has implications for the timing of

28 sampling human milk for exposure assessment purposes. We examined this issue by measuring

29 concentrations of polybrominated diphenyl ethers (PBDEs), hexabromocyclododecanes

30 (HBCDs), the HBCD degradation products tetrabromocyclododecenes (TBCDs), and

31 tetrabromobisphenol-A (TBBP-A) in human milk collected in 2010-11 from 10 first-time

32 mothers from Birmingham, UK. To evaluate whether concentrations varied significantly over the

33 first 12 months post-partum, 12 samples were taken - one per month - from each mother,

34 amounting to 120 samples overall. While concentrations of most of our target contaminants

35 displayed no significant variation $(p>0.1)$ over the duration of our study, significant increases

36 were detected in concentrations of $\Sigma T B C D$ s $(p=0.029$, average increase $1.4 \% /$ month) and BDE-

$37153(\mathrm{p}=0.058$, average increase $4.2 \% / \mathrm{month})$. When compared to data obtained from a different

38 set of UK mothers from a related but geographically wider catchment area sampled

39 contemporaneously to this study, the ratio of median concentrations of BDE-153 to BDE-99 was

40 markedly lower in the current study (0.46 compared to 1.32$)$. This may reflect unidentified

41 differences in exposure of the participants in the two studies. 


\section{Introduction}

44 Polybrominated diphenyl ethers (PBDEs), hexabromocyclododecane (HBCD), and

45 tetrabromobisphenol-A (TBBP-A) are chemicals that have found extensive global use as flame

46 retardants incorporated within a wide range of goods and materials, such as electrical and

47 electronic items, and soft furnishings. The extensive use of such brominated flame retardants

48 (BFRs) has led to demonstrable contamination of both indoor and outdoor environments ${ }^{1}$.

49 Contact with such contamination has led to human exposure via pathways such as inhalation of

50 air, and ingestion of both food and indoor dust, and resulted in the ubiquitous presence of BFRs

51 in humans ${ }^{2,3}$. As with other persistent organic chemicals, concerns exist about the presence of

52 BFRs in human milk. While studies to date of BFRs in human milk are consistent in

53 demonstrating that breast-fed infants are exposed substantially via ingestion of human milk ${ }^{4,5}$;

54 conflicting findings have emerged from the small number of studies that have examined the

55 temporal variation in concentrations of PBDEs in human milk from individual women over

56 extended periods of lactation. Essentially, while some authors have reported no discernible

57 consistent decrease of PBDE concentrations in human milk with increasing duration of lactation ${ }^{6}$,

58 7; others report PBDE concentrations in human milk over the first 6-18 months of lactation to

59 decrease $\mathrm{e}^{8,9}$. Whether such temporal declines in PBDE contamination of human milk occur is of

60 importance, as substantial reduction of concentrations over the course of lactation would mean

61 analysis of milk samples taken soon after birth will both overestimate exposure of the nursing

62 infant over the full period of lactation, as well as the reduction in mothers' body burdens as a

63 consequence of lactation.

64 Given this background, we report here a study of human milk samples taken every month over 65 the first year of lactation from 10 primiparas from Birmingham, UK. For each of these samples, 
66 we report concentrations of PBDEs (including BDE-209), $\alpha-, \beta-$, and $\gamma$-HBCDs, the HBCD

67 degradation products tetrabromocyclododecenes (TBCDs), and TBBP-A. To our knowledge,

68 these are the first data on temporal variation in concentrations in human milk from the same

69 women, of TBCDs, and TBBP-A, as well as the first such data for individual HBCD

70 diastereomers.

71

72 Methodology

73 Sample collection

74 Breast milk samples (each comprising $\sim 50 \mathrm{~mL}$ ) were obtained from 10 adult volunteers via

75 Birmingham Women's Hospital Milk Bank, following approval of the study protocol by

76 Warwickshire Research Ethics Committee and the R\&D Department in Birmingham Women's

77 NHS foundation trust. Informed consent was obtained from all participants before sample

78 collection. Recruitment criteria were that mothers were healthy primiparas aged between 18 and

7935 , who were prepared to bring samples to the Milk Bank every month for the 12 month duration

80 of the study. Samples collected in 2010-11 were kept in clean screw-capped glass containers and

81 transferred from the Milk Bank to the laboratory in special ice boxes then stored at $-20^{\circ} \mathrm{C}$ until

82 the time of analysis. Due to ethical regulations, the samples were collected in a completely

83 anonymous fashion with all participant information kept strictly confidential. For the purposes of

84 this study, a total of 12 milk samples were collected at monthly intervals from each mother

85 commencing in the first month post-partum. All participants completed the study fully, with

86 samples collected according to the same protocol by each participant throughout the course of

87 the study. 


\section{Sample extraction}

Samples were first freeze-dried, following the addition of $25 \mathrm{ng}$ of each of ${ }^{13} \mathrm{C}$-labeled BDE-47, BDE-99, BDE-153, BDE-209, TBBP-A, $\alpha-, \beta$ - and $\gamma$-HBCDs as internal (surrogate) standards. Accurately weighed aliquots of the freeze-dried samples $(\sim 2 \mathrm{~g})$ were loaded into pre-cleaned 66 mL Accelerated Solvent Extraction (ASE 300, Dionex Inc., UK) cells containing $1.5 \mathrm{~g}$ florisil, 3 g alumina, $5 \mathrm{~g}$ anhydrous $\mathrm{Na}_{2} \mathrm{SO}_{4}$ and hydromatrix (Varian Inc., UK) to fill the void volume of the cells and spiked with $25 \mathrm{ng}$ each of $\mathrm{d}_{18}-\alpha-\mathrm{HBCD}$ and ${ }^{13} \mathrm{C}-\mathrm{BDE}-154$ as QA/QC standards to evaluate losses due to extraction and clean-up. The ASE cells were extracted with hexane:dichloromethane $(1: 9, v / v)$ at $90{ }^{\circ} \mathrm{C}$ and $1500 \mathrm{psi}$. The heating time was 5 minutes, static time 4 min, purge time $90 \mathrm{~s}$, flush volume 50\%, with three static cycles. The lipid weight of the studied samples was determined gravimetrically on separate aliquots using a standard procedure (European Standard EN 1528-2, 1996; see supporting information for a summary).

\section{Extract purification}

The crude extracts were concentrated to $0.5 \mathrm{~mL}$ using a Zymark Turbovap ${ }^{\circledR}$ II (Hopkinton, MA, USA) then washed with $3 \mathrm{~mL}$ of $98 \%$ sulfuric acid. After phase separation, the hexane layer was transferred onto a florisil column (1.5 g of 5\% deactivated florisil, 60-100 mesh, topped with $1 \mathrm{~g}$ of Sigma-Aldrich, UK)anhydrous sodium sulfate (Sigma-Aldrich, UK) and eluted with $25 \mathrm{~mL}$ of hexane:dichloromethane $(1: 1, \mathrm{v} / \mathrm{v})$. The eluate was evaporated to dryness under a gentle stream of $\mathrm{N}_{2}$ and the dried extract reconstituted in $200 \mu \mathrm{L}$ of methanol containing $25 \mathrm{pg} \mu \mathrm{L}^{-1}$ of both ${ }^{13} \mathrm{C}_{12}$-BDE-100 and $\mathrm{d}_{18}-\gamma-\mathrm{HBCD}$ used as recovery determination (or syringe) standards to determine recoveries of internal standards for QA/QC purposes. 
$112 L C-M S / M S$ analysis of PBDEs, HBCDs and TBBP-A

113 Concentrations of target BFRs were determined using an LC-MS/MS system composed of a dual

114 pump Shimadzu LC-20AB Prominence liquid chromatograph equipped with SIL-20A

115 autosampler, a DGU-20A3 vacuum degasser coupled to a Sciex API 2000 triple quadrupole mass

116 spectrometer. The mass spectrometer was operated in atmospheric pressure photoionization

117 mode (APPI) for the determination of PBDEs, and in electrospray ionization mode (ESI) to

118 determine HBCDs, TBCDs, and TBBP-A. Full details of the multi-residue analytical

119 methodology used for separation and quantification of our target compounds can be found

120 elsewhere ${ }^{4,5,10,11}$.

121

122 Quality assurance/quality control

123 Full details of internal standard recoveries, field/method blanks, and method accuracy (measured

124 by comparing our data with certified/indicative values for HBCDs and PBDEs for replicate 125 analyses of NIST SRM2585, and matrix spikes at three concentration levels) have been reported

126 previously ${ }^{4,5}$. A summary of these data is provided as supplementary information. Limits of 127 quantification (LOQ) are also provided as SI. Where an analyte was <LOQ in a sample, it was 128 substituted for the purposes of statistical analysis by $\mathrm{f} x \mathrm{LOQ}-$ where $\mathrm{f}=$ fraction of samples in 129 which the analyte was present $>$ LOQ.

131 RESULTS AND DISCUSSION

132 Concentrations and patterns of BFRs in this study compared to other studies

133 Table 1 presents a statistical summary of concentrations of our target BFRs in this study, 134 together with comparative data from selected other studies of BFRs in human milk. Table SI-1 
135 gives concentrations of our target BFRs in every sample analyzed in this study. Concentrations 136 of HBCDs and TBBP-A in this study fall within the range of those reported previously by our 137 research group for single milk samples collected within the first 3 months post-partum from 35 138 women in the West Midlands conurbation ${ }^{4}$. This confirms that concentrations in UK mothers 139 exceed $\sim 5$ fold those in Boston, $\mathrm{USA}^{15}$, and are a little higher than those in Irish mothers ${ }^{20}$. 140 Moreover, the HBCD diastereomer pattern is consistent with our previous study and most other 141 studies worldwide. Specifically, $\alpha$-HBCD was the predominant diastereomer observed 142 contributing between 60 and $89 \%$ of $\Sigma$ HBCDs, with an average of $79 \%$. For comparison, $\alpha-$ 143 HBCD contributed 62-95\% $\Sigma$ HBCDs in our earlier study ${ }^{4}$. With respect to TBBP-A, 144 concentrations in this study are well below those of PBDEs and HBCDs - likely due to the short 145 human half-life of TBBP-A ${ }^{14}$ - and are consistent with the small number of previous reports of 146 the presence of TBBP-A in human milk ${ }^{4,19,20}$.

147 Our data also confirm previous reports of the presence of BDE-209 in human milk for which 148 previous data are more limited than for other PBDEs, as well as providing only the second report 149 of the presence of TBCDs in humans. As stated previously, the origins of TBCDs in humans are 150 unclear; while they have been detected in indoor dust ${ }^{12}$, they have also been shown to be formed 151 as HBCD metabolites in in vitro experiments involving cultured human hepatocytes ${ }^{13}$. Of note, is 152 the fact that median concentrations in this study of PBDEs 47, 153, and 209 are all lower than 153 reported in our earlier study of single milk samples ${ }^{5}$. Furthermore, while in our earlier study, 154 BDE-153 was more prevalent than BDE-99; the reverse was true in this study, and indeed 155 median concentrations of BDE-99 are higher in the current study. As all QA/QC criteria in this 156 study were met, and identical sampling, storage, and analytical protocols were followed in both 157 studies, we do not believe these differences to result from measurement artefacts. Moreover, the 
158 relative abundance of BDEs-99 and -153 in samples taken in this study during the first 3 months 159 post-partum (samples in our earlier studies were collected during this period), was not 160 discernibly different to those in later samples. Hence, the different timing of sample procurement 161 in the two studies does not account for the different congener pattern. In addition, while the 162 average age of participating mothers in the current study was 26.3 years, slightly lower than that 163 of the mothers in the earlier study (28.3 years), the difference was not significant (t-test, $\mathrm{p}>0.1)$. 164 Moreover, the mothers in both studies were all primiparas. Instead, we believe that the different 165 congener pattern in the current study, reflects unidentified differences in exposure of the 166 participants in the two studies. Pertinently, mothers in the current study did not participate in our 167 earlier survey, and came from a more geographically restricted area close to the Birmingham 168 Women's Hospital compared to participants in the earlier study who were recruited from across 169 the West Midlands conurbation. Interestingly, based on data suggesting that BDEs-47 and -99 170 display shorter human half-lives than BDE-153 ${ }^{14}$; Thomsen et $\mathrm{al}^{18}$ identified an exposure 171 scenario consistent with our observations. Specifically, they hypothesized that mothers with low 172 background exposure due mainly to diet would be expected to be exposed to a higher proportion 173 of BDE-153. Conversely, mothers receiving major direct exposure via contact with flame 174 retarded products and indoor dust would display higher relative abundance of BDE-47 and BDE17599 in breast milk.

176 Comparison of our data with recent studies conducted in the $\mathrm{US}^{7}$, New Zealand ${ }^{16}$, and elsewhere 177 in Europe ${ }^{17-20}$ (Table 1) reveals mothers in this study to display concentrations of BDEs- 47, -99, 178 and -153 that are in line with those from other regions, with the exception of the USA, in which 179 concentrations of these congeners in humans are much higher than elsewhere in the world ${ }^{7}$. In 180 contrast, as noted previously ${ }^{5}$, the elevated concentrations of BDE-209 in UK indoor dust 
181 compared to other countries ${ }^{21}$ are not reflected in similarly elevated concentrations of this 182 congener in human milk from UK mothers compared to women from other locations. While this 183 may indicate poor bioavailability of BDE-209 from indoor dust ${ }^{22}$, we note that BDE-209 184 concentrations in West Midlands mothers are lower than those detected in 6 mothers from north 185 east England ${ }^{17}$, and further data are required to ascertain whether the low BDE-209 186 concentrations in this study reflect a specific exposure pattern of our participants that is atypical 187 of UK women in general.

\section{Temporal variations in concentrations of BFRs in milk from individual mothers}

To evaluate whether concentrations of individual BFRs exhibited significant variation over the

full year of lactation for our 10 participants, we plotted concentrations of individual BFRs in each monthly sample as a percentage of the concentration detected in the first sample from the same mother. The plots obtained for BDE-47, BDE-153, $\Sigma$ HBCDs, and $\Sigma$ TBCDs are provided as the exception of BDE-153 and $\Sigma$ TBCDs, correlation analysis of these plots (conducted using Excel for Mac 2008) revealed there to be no significant change in concentration with time over

197 the 12 months lactation covered by this study. In contrast, concentrations of both BDE-153 and $\Sigma$ TBCDs show a significant increase (average increase $4.2 \%$ and $1.4 \%$ /month respectively) in concentrations during our study ( $\mathrm{p}=0.058$ and $\mathrm{p}=0.029$ respectively).

201 from 10 women in Oslo, Norway at monthly intervals on between 3 and 10 separate occasions

202 per mother ${ }^{9}$. The authors reported that when normalized to concentrations in the first sample of 203 each mother, concentrations of PBDEs 28, 47, 99, 100, 153, and 154 in subsequent samples 
204 displayed a significant decrease over the period studied. These decreases ranged between 205 1.7\%/month for BDE-153 and 4.7\%/month for BDE-154. A similar study of primiparae women 206 from California, reported PBDE concentrations in milk sampled every 4 weeks on 6 occasions 207 from birth for 9 women, and in milk sampled on 2 occasions at varying time intervals between 20818 and $>85$ weeks from birth for a further 9 women $^{8}$. The authors of this study reported 209 concentrations of BDE-47 to decline significantly by $3 \% / \mathrm{month}$ on average, and $2 \% /$ month on 210 average for both BDE-99 and BDE-100.

211 Clearly, our data contrast with these studies. However, they are consistent with the observations 212 of two other studies ${ }^{6,7}$. In the first of these, in which milk was sampled from 9 mothers on 213 between 2 and 4 occasions up to nearly 1 year post-partum, concentrations of BDE-153 showed 214 an increase in 7 mothers $(p=0.09)$, but no clear, consistent decrease or increase was observed for 215 any other targeted PBDEs ${ }^{6}$. In the second study, concentrations of PBDEs were measured in milk 216 samples collected from 83 women at both 3 and 12 months post-partum ${ }^{7}$. As in the first study, 217 while concentrations of BDE-153 were significantly higher in the 12 month samples $(\mathrm{p}=0.005)$, 218 no significant change was observed for all other monitored PBDEs.

219 LaKind et $\mathrm{al}^{6}$ offered two hypotheses to account for whether concentrations of POPs like PBDEs 220 will change over the duration of lactation. The congener pattern observed in our study, whereby no significant temporal change was observed for most contaminants, but significant increases 222 were seen for BDE-153 and $\Sigma$ TBCDs; may conceivably be reconciled with the first of these 223 hypotheses, that fluctuations in mothers' intake over the period monitored can influence 224 concentrations in human milk. While little is known about human exposure to TBCDs, as 225 highlighted above, Thomsen et $\mathrm{al}^{18}$ identified that for PBDEs, a transition from exposure driven 226 principally by indoor pathways such as direct contact with flame-retarded goods and indoor dust, 
227 to background exposure driven mainly by diet, could result in an increase in the relative 228 abundance of BDE-153 compared to BDEs 47 and 99. Given the hypothesized time-lag between 229 reductions in PBDE exposure via the diet following reductions in indoor contamination ${ }^{23}$ it is not 230 inconceivable that our data is an indication of a response of the exposure of the UK population to 231 PBDEs as a result of actions taken within the EU in the mid-2000s to restrict manufacture and 232 use of the Penta- and Octa-BDE products.

233 The second hypothesis advanced by LaKind et al is that substantial post-partum weight loss can 234 lead to increased (or at least less decreased) concentrations as a result of increased remobilization 235 of contaminants associated with adipose tissue. Although due to the ethical constraints of our 236 study, we do not have any information on the weight of our study participants, this does not at 237 first seem a credible explanation for our data, given that concentrations increased for only two of 238 our target contaminants. However, as these contaminants include BDE-153, for which recent 239 human biomonitoring studies consistently indicate is constituting an increasing proportion of the 240 SPBDE burden in human tissues ${ }^{5,18,20}$, as a result of its greater persistence relative to other 241 congeners ${ }^{14,24}$; it is possible that our data reflect the impact of post-partum weight loss on BFR 242 concentrations in our participants over a year of lactation. This could conceivably result in no 243 overall temporal change for most BFRs, but an increase for BDE-153 given the temporal 244 increase of this congener relative to other PBDEs reported elsewhere. If true, then this implies 245 enhanced persistence in humans of $\Sigma$ TBCDs relative to the parent HBCDs and the related 246 PBCDs. In summary therefore, while we are unable to provide a definitive explanation for our 247 observations; neither hypothesis outlined by LaKind et al can be ruled out.

248 This study - which has the highest temporal resolution of any conducted hitherto - provides 249 substantial evidence that in a small group of UK mothers, concentrations in human milk of most 
250 PBDEs, HBCDs, and TBBP-A do not change significantly over the first year of lactation. In 251 contrast, concentrations of the more persistent BDE-153 congener, and the HBCD degradation 252 product $\mathrm{TBCD}$ display a significant increase over the same period. While a larger study 253 involving more mothers is required to confirm our findings, our data suggest that for most of the 254 major BFRs included in our study, human milk samples taken at any point in the first year post255 partum will provide a reasonably representative measure of the exposure of the mother and the 256 nursing infant. The reasons for the observed increase in concentrations of two BFRs are not 257 clear, but may be related to in vivo metabolic production of these contaminants. In practical 258 terms, the absence of any significant decline in BFR concentrations over the first year of 259 lactation, suggests that advice to nursing mothers to practice pumping and discarding milk in the 260 early stages of lactation (referred to colloquially as "pump and dump") in order to minimize 261 infant exposure to such contaminants ${ }^{8}$, is unlikely to be successful.

263 Acknowledgments

264 The authors acknowledge gratefully all the milk donors and the staff of Birmingham Women's 265 Hospital Milk bank (Heather Barrow, Jenny Harris and Anne Hemming). We also thank Kelly 266 Hard (R \& D manager at Birmingham Women's Hospital) for assistance in obtaining ethical 267 approval for this project.

269 Supplementary Information

270 Concentrations of all target contaminants in every sample analyzed; plots of concentrations of 271 BDE-99, BDE-209, TBBP-A, $\alpha-, \beta-$, and $\gamma$-HBCDs in each monthly sample as a percentage of 272 the concentration detected in the first sample from the same mother; as well as detailed 
273 descriptions of analytical methodology and QA/QC data. This information is available free of

274 charge via the Internet at http://pubs.acs.org/.

275

276 References

277 (1) Law, R. J.; Herzke, D.; Harrad, S.; Morris, S.; Bersuder, P.; Allchin, C. R. Levels and trends 278 of HBCD and BDEs in the European and Asian environments; with some information for 279 other BFRs. Chemosphere, 2008, 73, 223-241.

280

(2) Harrad, S.; de Wit, C. A.; Abdallah, M. A-E.; Bergh, C.; Björklund, J. A.; Covaci, A.; 281 Darnerud, P. O.; de Boer, J.; Diamond, M.; Huber, S.; Leonards, P.; Mandalakis, M.; Östman, C.; Småstuen Haug, L.; Thomsen, C.; Webster, T. F. Indoor Contamination with Hexabromocyclododecanes, Polybrominated Diphenyl Ethers and Perfluoroalkyl 285 Compounds: An Important Exposure Pathway for People? Environ. Sci. Technol. 2010, 44, 3221-3231.

286

(3) Frederiksen, M.; Vorkamp, K.; Thomsen, M.; Knudsen, L. E. Human internal and external exposure to PBDEs - a review of levels and sources. Int. J. Hyg. Environ. Health 2009, 212, 109-134.

(4) Abdallah, M.; Harrad, S. Tetrabromobisphenol-A, Hexabromocyclododecane and Its Degradation Products in UK Human Milk: Relationship to External Exposure. Environ. Int. 2011, 37, 443-448.

(5) Abdallah, M.; Harrad, S. Polybrominated diphenyl ethers in UK human milk: Implications for infant exposure and relationship to external exposure Environ. Int., 2014, 63, 130-136.

(6) Lakind, J. S.; Berlin, C. M.; Sjödin, A.; Turner, W.; Wang, R. Y.; Needham, L. L.; Paul, I. M.; Stokes, J. L.; Naiman, D. Q.; Patterson, D. G. Do human milk concentrations of 
296

297

298

299

300

301

302

305

persistent organic chemicals really decline during lactation? Chemical concentrations during lactation and milk/serum partitioning. Environ. Health Perspect. 2009, 117, 1625-1631.

(7) Daniels, J. L.; Pan, I. J.; Jones, R.; Anderson, S.; Patterson, D. G.; Needham, L. L.; Sjödin, A. Individual characteristics associated with PBDE levels in US human milk samples. Environ. Health Perspect. 2010, 118, 155-160.

(8) Hooper, K.; She, J.; Sharp, M.; Chow, J.; Jewell, N.; Gephart R.; Holden, A. Depuration of polybrominated diphenyl ethers (PBDEs) and polychlorinated biphenyls (PCBs) in breast milk from California first-time mothers (primiparae). Environ. Health Perspect. 2007, 115, $1271-1275$.

(9) Thomsen, C.; Haug, L. S.; Stigum, H.; Frøshaug, M.; Broadwell, S. L.; Becher, G. Changes in Concentrations of Perfluorinated Compounds, Polybrominated Diphenyl Ethers, and Polychlorinated Biphenyls in Norwegian Breast-Milk during Twelve Months of Lactation. Environ. Sci. Technol. 2010, 44, 9550-9556.

(10) Abdallah, M. A.; Harrad, S.; Covaci, A. Isotope dilution method for determination of polybrominated diphenyl ethers using liquid chromatography coupled to negative ionization atmospheric pressure photoionization tandem mass spectrometry: validation and application to house dust. Anal. Chem. 2009, 81, 7460-7467.

(11) Abdallah, M. A.; Harrad, S.; Covaci, A. Hexabromocyclododecanes and tetrabromobisphenol-A in indoor air and dust in Birmingham, U.K: implications for human exposure. Environ. Sci. Technol. 2008, 42, 6855-6861.

(12) Harrad, S.; Abdallah, M. A.; Covaci, A., Causes of variability in concentrations and diastereomer patterns of hexabromocyclododecanes in indoor dust. Environ. Int. 2009, 35, 573-579. 
(13) Abdallah, M. A-E.; Zhang, J.; Pawar, G.; Viant, M. R.; Chipman, J. K.; D'Silva, K.; Bromirski, M.; Harrad, S. High-resolution mass spectrometry provides novel insights into products of human metabolism of organophosphate and brominated flame retardants. Anal. Bioanal. Chem. 2015, 407, 1871-1883.

(14) Geyer, H. J.; Schramm, K. W.; Darnerud, P. O.; Aune, M.; Feicht, E. A.; Fried, K. W.; Henkelmann, B.; Lenoir, D.; Schmid, P.; McDonald, T. A., Terminal elimination half-lives of the brominated flame retardants TBBPA, HBCD, and lower brominated PBDEs in humans. Organohalogen Compounds 2004, 66, 3867-3872.

(15) Carignan, C.; Abdallah, M. A.; Wu, N.; Heiger-Bernays, W.; McClean, M.; Harrad, S.; Webster, T. Predictors of Tetrabromobisphenol-A (TBBP-A) and Hexabromocyclododecanes (HBCD) in Milk from Boston Mothers. Environ. Sci. Technol. 2012, 46, 12146-12153.

(16) Coakley, J.; Harrad, S.; Goosey, E.; Ali, N.; Dirtu, A. C.; Van den Eede, N.; Covaci, A.; Douwes, J.; Mannetje, A. Concentrations of polybrominated diphenyl ethers in matched samples of indoor dust and breast milk in New Zealand. Environ. Int., 2013, 255-261.

(17) Bramwell, L.; Fernandes, A.; Rose, M.; Harrad, S.; Pless-Mulloli, T. PBDEs and PBBs in human serum and breast milk from cohabiting UK couples Chemosphere, 2014, 116, 67-74.

(18) Thomsen, C.; Stigum, H.; Froshaug, M.; Broadwell, S. L.; Becher, G.; Eggesbo, M. Determinants of brominated flame retardants in breast milk from a large scale Norwegian study. Environ. Int. 2010, 36, 68-74.

(19) Antignac, J. P.; Cariou, R.; Maume, D.; Marchand, P.; Monteau, F.; Zalko, D.; Berrebi, A.; Cravedi, J. P.; Andre, F.; Le Bizec, B. Exposure assessment of fetus and newborn to brominated flame retardants in France: preliminary data. Mol. Nutr. Food. Res. 2008, 52, $258-265$. 
342 (20) Pratt, I.; Anderson, W.; Crowley, D.; Daly, S.; Evans, R.; Fernandes, A.; Fitzgerald, M.; 343 Geary, M.; Keane, D.; Morrison, J. J.; Reilly, A.; Tlustos, C. Brominated and fluorinated 344 organic pollutants in the breast milk of first-time Irish mothers: is there a relationship to $345 \quad$ levels in food? Fd. Ad. Contam: A, 2013, 30, 1788-1798.

346 (21) Harrad, S.; Ibarra, C.; Diamond, M.; Melymuk, L.; Robson, M.; Douwes, J.; Roosens, L.; 347 Dirtu, A. C.; Covaci, A. Polybrominated diphenyl ethers in domestic indoor dust from 348 Canada, New Zealand, United Kingdom and United States. Environ. Int. 2008, 34, 232-238.

349 (22) Abdallah, M. A.-E.; Tilston, E.; Harrad, S.; Collins, C. In vitro assessment of the 350 bioaccessibility of brominated flame retardants in indoor dust using a colon extended model 351 of the human gastrointestinal tract. J. Environ. Monit. 2012, 14, 3276-3283.

352 (23) Harrad, S.; Diamond, M. Exposure to Polybrominated Diphenyl Ethers (PBDEs) and 353 Polychlorinated Biphenyls (PCBs): Current and Future Scenarios. Atmos. Environ. 2006, 40, $354 \quad 1187-1188$.

355 (24) Thuresson, K.; Hoglund. P.; Hagmar, L.; Sjodin, A.; Bergman, A.; Jakobsson, K. 356 Apparent half-lives of hepta- to deca-brominated diphenyl ethers in human serum as 357 determined in occupationally exposed workers. Environ. Health Perspect. 2006, 114, 176358 181. 
Table 1: Summary of Concentrations (ng $\mathrm{g}^{-1}$ lipid weight) of Target BFRs in Human Milk in this Study and Others

\begin{tabular}{|c|c|c|c|c|c|c|c|c|c|c|c|}
\hline $\begin{array}{l}\text { Location ( } n=\text { number } \\
\text { of participants) }\end{array}$ & $\begin{array}{l}\text { Year of } \\
\text { Sample } \\
\text { Collection }\end{array}$ & Parameter & $\begin{array}{l}\text { BDE- } \\
47\end{array}$ & $\begin{array}{l}\text { BDE- } \\
99\end{array}$ & $\begin{array}{l}\text { BDE- } \\
153\end{array}$ & $\begin{array}{l}\text { BDE- } \\
209\end{array}$ & $\begin{array}{l}\alpha- \\
\text { HBCD }\end{array}$ & $\begin{array}{l}\beta- \\
\text { HBCD }\end{array}$ & $\begin{array}{l}\gamma- \\
\text { HBCD }\end{array}$ & $\Sigma$ TBCDs & TBBP-A \\
\hline Birmingham, UK & & $5^{\text {th }} \%$ ile & 0.89 & 0.38 & 0.07 & 0.05 & 1.64 & 0.09 & 0.12 & 0.01 & 0.03 \\
\hline from each & & Average & 2.97 & 1.58 & 0.51 & 0.14 & 5.27 & 0.48 & 0.79 & 0.14 & 0.06 \\
\hline participant), this study & $2010-11$ & $95^{\text {th }} \%$ ile & 6.93 & 4.26 & 1.09 & 0.39 & 15.1 & 1.49 & 2.10 & 0.38 & 0.17 \\
\hline & & $\mathrm{DF}^{*}(\%)$ & 100 & 100 & 100 & 63 & 100 & 100 & 100 & 92 & 61 \\
\hline $\begin{array}{l}\text { Birmingham, UK } \\
(\mathrm{n}=34)^{5}\end{array}$ & 2010 & Median & 2.80 & 0.69 & 0.91 & 0.25 & NR & NR & NR & NR & NR \\
\hline $\begin{array}{l}\text { North East England, } \\
\text { UK }(n=6)^{17}\end{array}$ & $2011-12$ & Median & 2.05 & 0.97 & 0.93 & 0.70 & NR & NR & NR & NR & NR \\
\hline $\begin{array}{l}\text { Boston, MA, USA } \\
(\mathrm{n}=43)^{15}\end{array}$ & $2005-06$ & $\begin{array}{l}\text { Geometric } \\
\text { Mean }\end{array}$ & NR & NR & NR & NR & 0.71 & 0.08 & 0.20 & 0.05 & $<0.03 \mathrm{NR} 0.55^{\mathrm{a}}$ \\
\hline France $(n=23)^{19}$ & 2005 & Median & NR & NR & 0.83 & 1.50 & $\mathrm{NR}$ & $\mathrm{NR}$ & NR & $\mathrm{NR}$ & 0.17 \\
\hline Ireland $\left(\mathrm{n}=11^{\mathrm{c}}\right)^{20}$ & 2010 & Median & 1.11 & 0.27 & 1.00 & $0.77^{\mathrm{d}}$ & $2.59^{\mathrm{e}}$ & $0.42^{\mathrm{e}}$ & $0.43^{\mathrm{e}}$ & NR & $0.05^{\mathrm{e}}$ \\
\hline New Zealand $(n=33)^{16}$ & 2010 & Median & 2.14 & 0.56 & 0.75 & 0.19 & NR & $\mathrm{NR}$ & $\mathrm{NR}$ & NR & NR \\
\hline
\end{tabular}

Harrad and Abdallah, 2015 Page 18 of 20 
$365 *$ DF refers to detection frequency; $* *$ NR indicates the value was not reported.

Harrad and Abdallah, 2015 Page 19 of 20

ACS Paragon Plus Environment 
366

367

368

369

370

371

372

373

Figure 1: Concentrations of BDE-47, BDE-153, $\Sigma$ HBCDs, and $\Sigma$ TBCDs normalized to the first sample

\section{BDE-47}

\section{BDE-153}
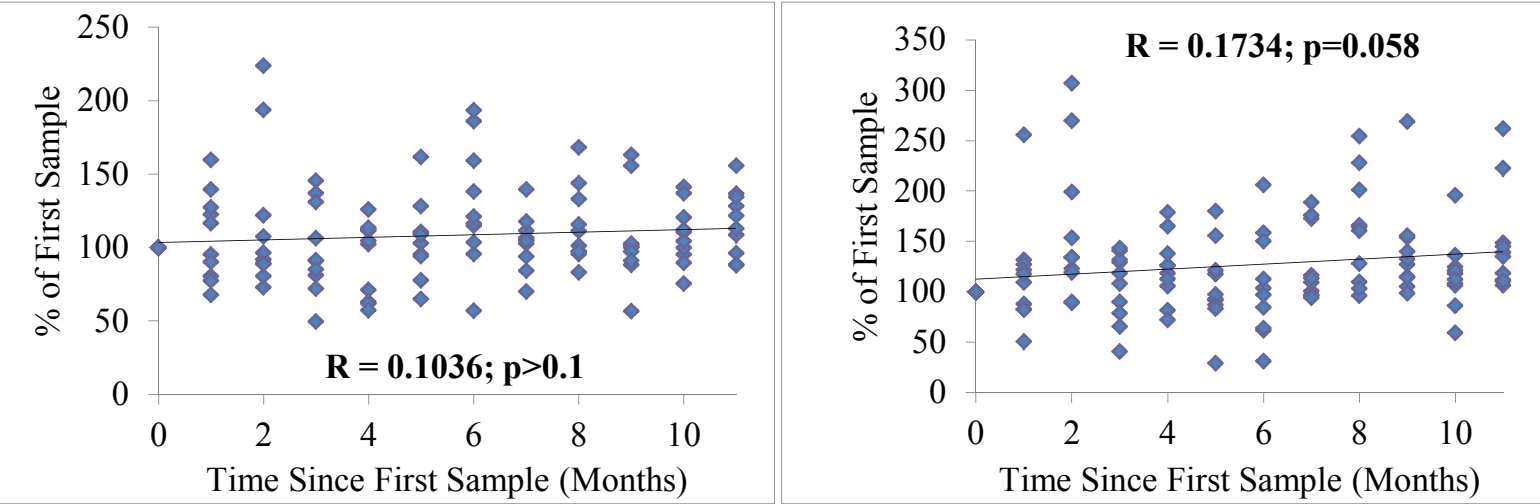

\section{$\Sigma$ HBCDs}

\section{$\Sigma$ TBCDs}
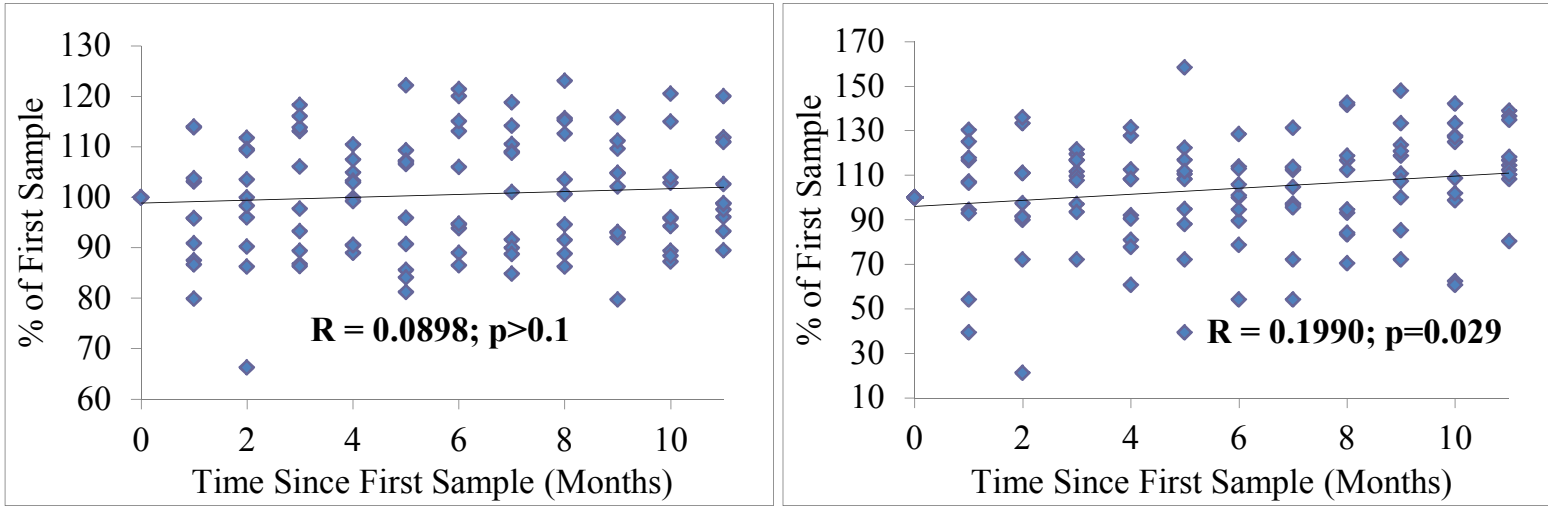